Chapman University

Chapman University Digital Commons

Film Studies (MA) Theses

Dissertations and Theses

Spring 5-2021

\title{
Cinematic Palimpsests: Polysemy and In(ter)dependency in the Spectator Experience
}

\author{
Lyric Luedke \\ Chapman University, luedke@chapman.edu
}

Follow this and additional works at: https://digitalcommons.chapman.edu/film_studies_theses

Part of the Film and Media Studies Commons

\section{Recommended Citation}

Luedke, Lyric. Cinematic Palimpsests: Polysemy and In(ter)dependency in the Spectator Experience. 2021. Chapman University, MA Thesis. Chapman University Digital Commons, https://doi.org/10.36837/ chapman.000239

This Thesis is brought to you for free and open access by the Dissertations and Theses at Chapman University Digital Commons. It has been accepted for inclusion in Film Studies (MA) Theses by an authorized administrator of Chapman University Digital Commons. For more information, please contact laughtin@chapman.edu. 
Cinematic Palimpsests:

Polysemy and In(ter)dependency in the Spectator Experience

\author{
A Thesis by \\ Lyric Luedke \\ Chapman University \\ Orange, CA \\ Dodge College of Film and Media Arts \\ Submitted in partial fulfillment of the requirements for the degree of \\ Master of Arts in Film Studies
}

May 2021

Committee in charge:

Dr. Kelli Fuery (Chair)

Dr. Patrick Fuery

Dr. Federico Pacchioni 
The thesis of Lyric Luedke is approved.

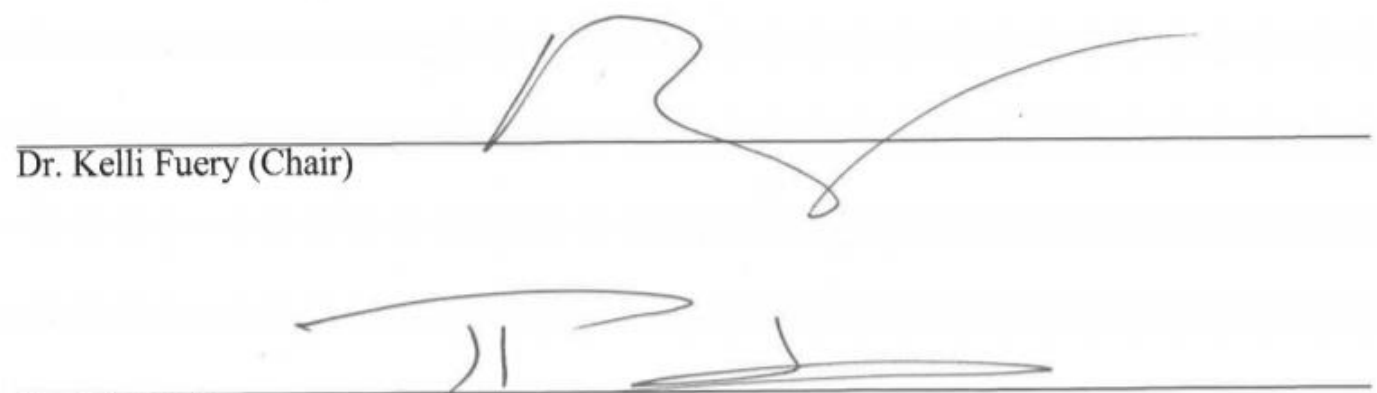

\section{Dr. Patrick Fuery}

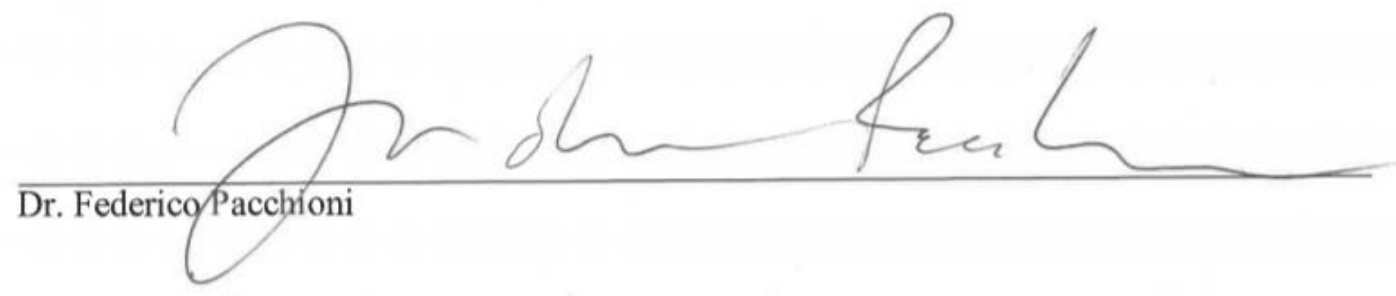

April 2021 


\section{Cinematic Palimpsests:}

Polysemy and In(ter)dependency in the Spectator Experience

Copyright (C) 2021

by Lyric Luedke 


\author{
ABSTRACT \\ Cinematic Palimpsests: \\ Polysemy and In(ter)dependency in the Spectator Experience \\ by Lyric Luedke
}

The model of the cinematic palimpsest helps us to critically reevaluate formal aspects of film language, relationships between film texts, and the construction of cinematic meaning in conversation with the spectator. Originating in Medieval Europe, a palimpsest is traditionally defined as a book or similar physical text "created by a process of layering whereby the existing text was erased, using various chemical methods, and the new text was written over the old one" again and again (Dillon 2005). Palimpsests rely on the core principle of in(ter)dependency, wherein each element or layer is both independent and interdependent, inherently affecting the significance of other elements around it and being affected in turn by those other elements. In this study, the theoretical model of the palimpsest is applied to three aspects of the cinematic experience, from the intra- to the inter- and extratextual levels. Emphasizing the multiplicity of the lived experience of cinematic viewership, the model seeks to explain the intersubjective, dialogic relationship of the human mind to the media technologies it encounters on a regular basis in the $21^{\text {st }}$ century. 


\section{TABLE OF CONTENTS}

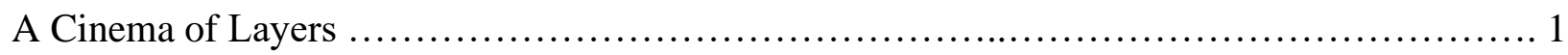

Film Language and the Intratextual Palimpsest .................................... 11

Texts in Conversation in the Intertextual Palimpsest .................................. 18

Intersubjectivity and the Extratextual Palimpsest ................................... 22

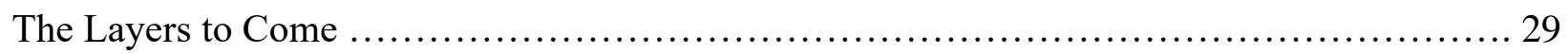

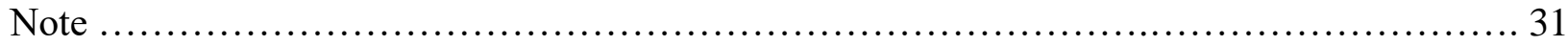

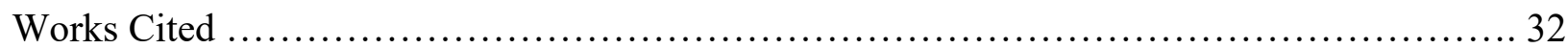




\section{A Cinema of Layers}

More important than genre, time period, or nation of origin, the structural model of film language and its construction of meaning in conversation with the spectator can be elucidated by the model of the palimpsest. Originating in Medieval Europe, a palimpsest is traditionally defined as a book or similar physical text "created by a process of layering whereby the existing text was erased, using various chemical methods, and the new text was written over the old one" again and again (Dillon 244). The necessity for this continuous reuse of materials during the Middle Ages arose due to a combination of factors, including the difficulty in sourcing writing materials prior to the mass production of paper, the natural deterioration of ill-preserved existing texts, and shifting ideas of what texts or written languages should be preserved or allowed to deteriorate over time (244). In a more theoretical sense, however, the palimpsest can be thought of as any "involuted phenomenon where otherwise unrelated texts are involved and entangled, intricately interwoven, interrupting and inhabiting each other” (245). Thomas de Quincey (17851859), the 19th century essayist and author of Confessions of an English Opium Eater, likens the palimpsest to a membrane or membrana, made up of "endless strata," each bearing the imprint of the markings written and subsumed by subsequent markings on every one of the infinite layers (21). In cinema studies, the theoretical model of the palimpsest helps us to critically reevaluate the film text as a multiplicitous and polyphonous phenomenon of layered meaning, rather than as a singular and static document with a fixed meaning or set of canonical interpretations that preclude modification.

Jean Epstein asserts in 1946 that significance in cinema is derived largely from the combination or editing of shots, the smallest unit of film language perceptible to the human eye (The Intelligence of a Machine 14). Subsequent scholars have elaborated upon this idea, 
Christian Metz, for instance, describing how the shot, denoting a set of images or symbols, signifies in tandem with those images and symbols denoted by other shots in a sequence (74). The effects of each shot are multiplied, prompting more complex emotions and responses as shot sequences unfold. Thus, a horror film will generate feelings of suspense in spectators with intercutting and sudden changes in editing rhythm, while a dialogue-heavy drama's editing scheme gradually shows us who is speaking to whom, and how each character regards the other. The conventions of film and video media language, and of the encoded meanings of certain maneuvers, differ from country to country, from era to era, and from spectator to spectator, depending on the unique "syntagmatic chain of [the] discourse" at play in each case (Hall 163). Yet the basic structure of cinematic logic, linking individual shots in larger chains of significance before the eyes of the spectator, remains the same (Aumont 26).

The palimpsest model reaffirms these core components of cinematic language, explaining their function and import to the experience of film viewing. The overlapping, layered form of the palimpsest is analogous to the shot-layers that make up any cinematic text, which are layered in turn with those texts at the periphery of the originary one, and even with the unique subjectivity of each spectator in their experience of viewing. Unlike studies that prioritize either textual analysis or an exploration of the practices of spectatorship, the palimpsest provides a synthesized model of how cohesive significance is derived from three basic levels of cinema, in addition to how the spectator actively contributes to the processes of meaning-making through their lived experience of viewing.

The model of the palimpsest applies to three distinct planes, or levels, of the cinematic experience, which all overlap and influence each other in the act of film viewing. At the intratextual level, the palimpsest outlines the basic components of film language and the 
construction of meaning in the combination of in(ter)dependent shot-layers. At the intertextual level, separate texts or paratexts are considered as layers of a yet larger theoretical palimpsest through their related content or production context. Finally, at the extratextual level, the palimpsest illuminates the critical function of the spectator in assigning meaning to the signifying processes of cinema in a dialogic exchange between the text(s) and the sociocultural context it inhabits. Each of the three levels addresses a major component of cinematic meaningmaking, from the construction of the text itself to its role in a broader discourse of cinema and beyond. In sequence, however, they also build upon one another in a hierarchy of their importance to the processes of cinematic signification, the extratextual level and the relationship of the text to spectator(s) occupying the preeminent position. Without a spectator (or reader) to perceive and sense the layers of the palimpsest and join them in conversation to produce a meaningful interpretation, the significance of the intra-and intertextual levels, and all of the layers they encompass, would be rendered moot. In other words, without a spectator, the palimpsest can hardly be said to exist at all, making the extratextual level of the model crucial to its overall function. This final layer of the palimpsest, composed of the spectator who enters its structure in the activity of their interpretation, is necessarily as variable as the subject positions of an infinite number of potential spectators who may engage with a given text.

A brief clarification of terms is in order before situating cinematic palimpsest in its disciplinary context. It may seem more fitting to use the term 'pentimento,' which originally referred to layers of new images or strokes applied to a canvas to change the scene of a painting, to address the cinema ("Pentimento"). After all, film aesthetics are deeply rooted in the conventions of painting, and the two mediums are both visual, as opposed to the sense of the written word conveyed by the original literary palimpsests. However, given that 'palimpsest' is a 
term that carries the implication of added, or "reappear[ing]" meaning among the layers of a text, in favor of the subtractive, corrective, and replacing quality of the pentimento, the former is a more valuable and accurate model for a medium comprised of the sum of many slices of time and space (Dillon 245). Rather than one shot in a sequence replacing the prior shot, each holds simultaneous and equally important footing in the continuous chain of signification comprising any filmic text. The palimpsest model recognizes this fluid and dynamic nature of the moving picture's ontology and significance. It is a text which bears the traces of a theoretically infinite number of prior texts, each of which are differentiable yet indivisible by virtue of their in(ter)dependency, as described below. This is the same way shots function in cinema, each one distinct yet unequal to the sum of the film when taken out of its context in a sequence of other shots. Thus, the palimpsest model and the cinema are analogous to one another in the composition of their in(ter)dependent layered structure.

In this study, authors and works ranging both cinema and literary studies, including Mikhail Bakhtin's Problems of Dostoevsky's Poetics and The Dialogic Imagination, Sergei Eisenstein's Film Form, Stuart Hall's “Encoding/Decoding," Christian Metz's "Some Points in the Semiotics of the Cinema," and Gilles Deleuze's Cinema II have been put in conversation with one another. These works have been chosen both for their theoretical import and their widely differing approaches and disciplinary contexts, which resist a prescriptive definition of the ultimately "unthinkable" phenomenon of the palimpsest (Derrida 19). Together, these sources emulate the polyphonous quality of the palimpsest and trace its historical and theoretical evolution from literary studies to its present application to cinema. Beginning with the literary basis of the palimpsest as described in texts by De Quincey and Sarah Dillon above, then briefly moving into its application in the fundamentals of film studies before ultimately settling in 
contemporary cultural and media studies, the palimpsest is shown to transcend academic boundaries between subjects, metaphorically layering the scopes and methodologies of multiple disciplines in the totality of the theoretical model of the palimpsest. In part, this wide applicability is characteristic of the history of the oft-adapted model itself and its fundamental principle of in(ter)dependency among layers. More intentionally, then, this praxis of abstraction in writing is the methodology of choice for such an interdisciplinary and widely relevant project because it mirrors the ontology of the subject of the palimpsest in its very structure and form. When we speak about, analyze, or view the palimpsest, we are engaging in the intangible phenomenon that is the palimpsest itself, sometimes without even being conscious of doing so. Notably, the subject remains a crucial part of the palimpsest regardless of what discipline it is applied to, as evidenced by the necessity of the scientist perceiving light phenomena in Niels Bohr's Principle of Complementarity. ${ }^{1}$

The palimpsest model additionally serves as an effective poststructuralist device in cinema and media studies in its rejection of fixed or singular significance associated with the text. The text itself and its creator(s) are decentered by the spectator, who is not an objective figure, but approaches the interpretation of the text with their own unique subject position and life experience in mind. In contrast to previous theories such as Jean-Louis Baudry's apparatus theory, in which an ideal spectator is captivated by the illusion of continuous frames in the cinematic system, the palimpsest model places the spectator in the position of control over meaning interpreted from a given text (Baudry and Williams). The discontinuities of the cinematic system are evident, and it is the spectator's agency, rather than the filmmakers', which unifies them into a cohesive and comprehensible whole. Thus, the infinite possibilities of spectator subject positions give rise to an equally illimitable polyphony within the text and the 
theoretical palimpsest built within and around it. The text and its corresponding palimpsest(s) are in(ter)dependent upon one another, but differentiated in the model for ease of understanding as the fixed physical object of discussion (the text) and the fluid phenomenon of meaning-making that occurs between it and the world around it (the palimpsest). The spectator enters into and forms part of the palimpsest, while the text itself remains a separate, localizable object of examination.

The palimpsest is an inherently formalist model of cinema. There is no sense of objective truth or reality to the palimpsest, and the infinitude of its layers resists fixed or singular significance. Its application to cinema is supported in this thesis by categorically formalist thinkers such as Sergei Eisenstein, who theorized alongside his contemporaries in the early Soviet cinema that meaning is created through the contrapuntal arrangement of slices of time and movement. Rather than drawing from the harmonious logic of most experiences in the real world, they argued, the cinema should interpellate the spectator with a "unity of inter-penetrating opposites" that suggest new truths and ideas by their lack of natural association (Eisenstein 136). In similar structuralist terms, Julia Kristeva names the "transmission of essence through form" as the function of palimpsestuous texts such as novels or films (59). Conflict is necessary, she writes, as poetic language must be "double... not in the sense of the signifier/signified dyad, but... in terms of one and other" (40). Are we to assume, then, that realist cinema has no place in our discussion of the palimpsest? If "singularity is illusory" in the palimpsest, then how might we consider the documentary, experimental, or other non-narrative video media within the palimpsest model? (Raj 80 ). What of the new 21 st century forms of media we consume every day on social media or in the news? Even classical theorists focused on the signifying processes of popular film assert that the emphasis placed on narrative filmmaking is "a priority that must 
not of course become an exclusivity" (Metz 69-70). It is to cultural and media studies theorists like Stuart Hall that we must look for the answers to such questions, however. Whether narrative or non-narrative, video media can be analyzed through the lens of culturally encoded and decoded meanings, the "encoded" on one hand representing the intended meaning of the text's creator, and the "decoded" referring to the consumer's interpretation on the other (Hall 165). Once again, the decoding subject or spectator proves to be the fundamental component of the palimpsest, doing the necessary work of transforming stimuli of any variety into coherent cultural significance.

Brigette Peucker's work on intermediality suggests that we are only recently realizing the palimpsest model's applications to cinema as opposed to the more established arts. Like the palimpsest model itself, with its roots in literary studies, the "fissured" film text is seen as a hybrid composition of earlier media such as painting, theater and performance, and writing (Peucker 4). De Quincey is among a group of early cultural and art theorists who related the model of the palimpsest to the phenomena of human perception, memory, and cognition. Much like the palimpsest, the human mind is made up of "everlasting layers of ideas, images, feelings... each succession has seemed to bury all that went before. And yet, in reality, not one has been extinguished" (De Quincey 18). The example of survivors of near-death experiences, who often report recalling forgotten memories from early childhood in the moment of their crisis, could be considered proof of this (non)-erasure of our experience. Patients have also been known to re-access repressed memories of past traumas in therapeutic settings, or when exposed to particular sensory stimuli that were present in the initial repressed event. In the cinematic palimpsest, shot-layers that exist in the spectator's immediate past act the same way as the 
memories De Quincey describes, each one seemingly subsumed by the next, but in actuality always present in the signifying chain attached to the current shot-layer.

For Epstein, the phenomena of cinema itself is predicated upon the illusion of uninterrupted motion, or "primordial continuity," produced in the projection of individual, static frames much like our memory (The Intelligence of a Machine 13). His concept of photogénie takes up this illusion of movement, alongside a perception of the image's "personality...spirit visible in things and people" in the real world, as the core tenets of cinematic art ("On Certain Characteristics of Photogénie" 295). Jacques Aumont, also, emphasizes the shot's perpetual relationship to time and the ever-presence of past and future shots (26). Jacques Derrida references this phenomenon in his concept of the "trace," which asserts that signs are linked to one another by their very differentiation from other signs. The trace of a sign is "simultaneously living and dead" in the present moment, just as the shots of a film are always both present and absent by virtue of their in(ter)dependent relationship (24). We can see that even in early works of classical film theory such as Epstein's and Aumont's, the spectator's experience is viewed as a critical facet of the cinema's meaning-making, or perhaps even sense-making, facility. It is the spectator who perceives and senses the film text, and by extension, its overlapping temporalities.

The structure of the palimpsest model is defined by the combination of distinct parts, past and future, which create a unified present. Using the oft-cited analogy of the continuity of cinema to the perception of light, Epstein states that only through the apprehension of the most minute, distinct parts (shot-layers, or time-layers) of the film text as a continuous whole can we arrive at the "truth" of a given text (The Intelligence of a Machine 14). Like a pane of glass that shatters into innumerable unique shapes, Epstein writes, we must nevertheless recognize that the truth or reality of the pane "was only the unity it constituted" before the break occurred (15). The 
parts, each one a miniature whole in itself, are yet indivisible in the significance of the entire text, be it a pane of glass, a painting, a book comprised of many layers of writing, or a work of cinema. Paradoxically, we must bear in mind each infinitely reduced piece of the whole, relating them to one another in our lived experience of the whole, to understand its beauty and significance as a "unity of a higher order" (Eisenstein 254). This "truth" is greater than the sum of the parts that make up the whole, however. It also implies a significance of the whole that is not limited to the physical components it is composed of. Meaning exists intangibly in the spaces surrounding and between texts and those who would read or view them. While the palimpsest explains how parts are combined to form a whole, it also explores how meaning comes about from the simple components of a work and the effects it has on spectators and the world around them.

In the traditional definition of the palimpsest, referring to a tangible work of writing, as well as in the theoretical structure it connotes, the core principle of in(ter)dependency is crucial. In(ter)dependency indicates a structure in which each element is both independent, complete within itself and operating within definitive limits, and interdependent, that is, inherently affecting the significance of other elements around it and being affected in turn by those other elements. Paradoxically, the "fragmentation" of in(ter)dependent parts "is the basis of diegetic unity" in cinema (Silverman 146). These in(ter)dependent elements are referred to as "layers" in the context of the palimpsest, linking them back to the tangible layers of writing on the originary palimpsests of the Middle Ages. To use a literary term, one can conceive of in(ter)dependency in the cinematic palimpsest as a form of synecdoche, the spectator "receiv[ing] a presentation of the part instead of the whole" at any given moment in the viewing experience (Eisenstein 133). The principle of in(ter)dependency is not limited to the palimpsest model, however. There are 
similar ideas, albeit described in different terminology, underlying theoretical structures across a variety of disciplines, from the arts and media studies to science and technology.

For the purposes of this study, the palimpsest and its characteristic quality of in(ter)dependency are considered not as a fixed object or state of being, but as an ever-shifting, intangible phenomenon resulting in an in(ter)dependent structure of discontinuities arranged as a whole. We can liken the principle of in(ter)dependency here to Derrida's similar philosophical notion of différance, relating to "the complex structure of a weaving, an interlacing which permits the different threads and different lines of meaning... to go off again in different directions, just as it is always ready to tie itself up with others" (3). Derrida's words echo the palimpsest's sense of polyphony and open-endedness, as the infinity of its potential layers leads to an infinity of interpretations and understandings. While the cinematic palimpsest may have concrete layers such as shots, with clear limits in space and time, its larger structure is infinitely changing and expanding as new significant combinations arise in a pattern of non-arrival, just like the phenomenon of différance. The palimpsest is "immediately and irreducibly polysemic," each of its layers intersecting with all other layers in a limitless chain of meaning, not just those shots directly preceding and following the current one (Derrida 8). If the significance of the palimpsest cannot be fixed, however, what agent decides upon its meaning in any given movement, or from any given perspective? To define an object such as this, it is necessary for the subject (the reader, the spectator, etc.) to intervene in the process of meaning-making, drawing from their lived experience of the text(s) to make meaning from connections between a theoretically endless sea of layers. Each spectator's experience is unique, and even the same individual's experience may change in viewing a text in different settings or at different times, making the cinematic palimpsest a truly "infinitive" and polysemic structure defined not so much 
by the meaning is produces, but by the active dialogic processes by which that meaning is made conscious in those who would engage with it (9). Neither in différance nor in the in(ter)dependent palimpsest can an essential or objective spectator exist, but only one who actively and subjectively relates the "'present' element" (shot, motif, paratext, intertext, etc.) of the cinematic experience with past and future elements to create meaning (13).Thus, next to the principle of in(ter)dependency, a second condition for the ontology of the cinematic palimpsest exists in the individual spectator, who is both active and subjective in their approach to the text.

\section{Film Language and the Intratextual Palimpsest}

The intratextual level of the palimpsest deals with the most basic components of film language and their relationships to one another. The shot is key here, for while it "may convey

several informational elements" such as camera movement, costuming, contrapuntal auditory and visual stimuli, and so on, it "constitutes the largest minimum segment" of signification we can identify in a concrete, standardized form for the purposes of the semiotic project (Metz 74). Shot sequences can largely be "seen as the equivalent of syntactic ones in linguistic discourse," the replacement of any shot with another, or the rearrangement of a sequence, changing the overall meaning of a sequence either paradigmatically or syntagmatically, or both (Silverman 138). If the palimpsest considers each shot to be a layer of meaning akin to the partially erased layers of writing found on the original palimpsests of the Middle Ages, then each shot is in(ter)dependent on all those shots prior and subsequent to it in the film text to generate significance. This in(ter)dependent relationship between shots in cinema is not a new development made by the application of the palimpsest, although it is a core principle of the model. In fact, while it has been referred to by different names, in(ter)dependency is the basis of film semiotics, outlined 
perhaps most succinctly and most notably in Metz's 1974 Film Language: A Semiotics of the

Cinema. Film is a language, he suggests, each shot analogous to a word, shot sequences standing in for sentences, and optical devices such as wipes, dissolves, or other editing transitions serving as punctuation (74-75). Their combination creates entire cinematic sentences (sequences), which are further joined together to create paragraphs (scenes), chapters (acts), and finally, a complete story (the complete film text). The denotative nature of live action filming becomes connotative not only in the ordering and combination of shots, but in the involvement of the spectator, who uses the sensory stimuli provided by the text and their own cognition to piece together an interpretation or decoding of the text. That the components of film language, like those of written languages, "can be read only in juxtaposition... only when combined with a separately indicated" component is evident in both film semiotics and the in(ter)dependent structure of the cinematic palimpsest demonstrates the palimpsest's implication even in classical film theories such as Metz's (Eisenstein 65-66). The structure of the palimpsest has thus been indirectly associated with film for decades, and in some of film theory's seminal texts, albeit silently, or under the guise of different terminology and theoretical structures.

Sergei Eisenstein's eight "Methods of Montage" can also help us to understand the palimpsest on the intratextual level, as the defining structure of the combined elements within a single text. As stated above, film language, and especially editing, is predicated on the combination of disparate elements, whether those elements be separate shots, visual and auditory stimuli, colors, or the foreground and background of a single frame. Within shot sequences, "overtones" and "undertones" combine to create counterpoints and discursive space for multiplicitous interpretation (Eisenstein 66). Types of montage arranged in a hierarchy from "metric" to "intellectual" gradually convey the "dominant emotional sound" of the sequence, but 
the contrapuntal use of tones opens the text to various subject viewing positions (76). What Eisenstein takes pains to emphasize is a certain degree of inclusion of the spectator in the meaning-making processes of cinema, despite the director or editor's careful designing of shot sequences to serve a particular message. Metz tells us that 'to 'speak' cinematographic language" as a director would in constructing a film "is to a certain extent to invent it," while "on the other hand, movie spectators... constitute a group of users" (73). On the contrary, Eisenstein insists that the "psycho-physiological complex of the person on the perceiving end" of the film text is crucial to the significance of montage, or shot-layer compositions (80). Rather than simply decode the intended meaning of a director or writer, the spectator actively constructs meaning alongside the shots, as discussed further at the extratextual level of the palimpsest (below). Shotlayer compositions may give rise to any number of interpretations or experiences of viewing, each layer of the palimpsest signifying ad infinitum with each other layer, including the viewing subject or spectator.

Bakhtin similarly notes the derivation of meaning from contrapuntally linked elements in a text within the concept of polyphony or many voiced-ness. A polyphonous text is an “inherently dialogic structure" indicating "multiplicity within a singular text or statement," rather than between several texts within a broader discourse, as on the intertextual level of the palimpsest (Problems of Dostoevsky's Poetics 40). Bakhtin discusses the works of novelist Fyodor Dostoevsky in particular as being characterized by "a plurality of independent and unmerged voices... a plurality of consciousnesses, with equal rights and each with its own world, [which] combine but are not merged in the unity of the event" [italics mine] (6). Notice how the final words of this sentence establish the principle of in(ter)dependency crucial to the structure of the palimpsest even without directly seeking to describe such a structure. Bakhtin comments here 
on Dostoevsky's characters alone, each of whom hold different opinions, characterizations, and styles of dialogue that are put into conversation in his novels. Nevertheless, there is a connection in the structuring of these character-layers to the shot-layers of the cinema. Each shot represents its own slice of time and space carrying its own denotative and connotative significance, much like how characters or symbols in a novel each carry their own fictional perspective and significance. Although appearing in different mediums, the in(ter)dependent structure of these layers, each one a miniature totality of its own but dependent on all others to form the whole, remains the same within the model of the palimpsest.

Of course, cinema and literature differ significantly in that the former is a time-based medium, light captured over time adding an ontological dimension that the written word altogether lacks. Bakhtin's objects of study were not subject to the overlappings of present moments as the cinema is. Departing from the image of the physical palimpsests of the Middle Ages, where layers of writing appear one on top of another, we can visualize the structure of shot-layers within a cinematic palimpsest in Gilles Deleuze's concept of the crystal-image and the model of the "inverse cone" (98). Deleuze, like Eisenstein, sees shot sequences as groupings made not by "association, but... differentiation," a new image added to an old one "which will induce an interstice between the two" (179-181). The crystal-image explains how disparate elements can be combined into a unitary structure such as a palimpsest through the simultaneity of the temporalities that the shots represent. The crystal-image is a form of time-image, an image which "enter[s] into relation with its own virtual image... an image which is double-sided, mutual, both actual and virtual" (273). Such images encompass past and future in the present they constitute, and absence in their very presence, each shot being a so-called present that the spectator associates with the previous shot and the shot to come. "The simultaneity of peaks of 
present" and "the coexistence of sheets of virtual past" theoretically layer atop one another in much the same sense as the vellum of the Medieval palimpsests display layers of writing of successive ages and moments in time (101-105). In this light, the shot-layer of the cinematic palimpsest is perhaps more accurately considered as a time-layer, the equivalent in film to the word-layer in writing. Unlike in literature, however, the linearity of the written narrative is replaced by overlapping temporalities that make the spectator's experience always one of paradox and multiplicity. As in Derrida's philosophy of différance, the time-image in cinema is "non-localizable," existing as a perceived phenomenon of oscillation between past, present, and future, rather than a static, tangible object (Toubiana 49). It relies upon our consciousness of it to make meaning, and as such exists in a sense within us, "never ceas[ing] to trace and retrace the circuits of the brain" with which we sense it (49).

Charlie Kaufman's 2020 I'm Thinking of Ending Things demonstrates the in(ter)dependency of temporalities described by Deleuze's crystal-image in a more literal fashion through the construction of its non-linear narrative. In the film, an unnamed young woman and her boyfriend witness the collapse of their past, present, and future selves while on a trip to his hometown. From shot to shot, representations of each character (down to their physical appearance) and the places they inhabit switch between alternate timelines, the unifying space of the boyfriend's family home linking them together throughout the first half of the story. In one scene, for instance, the young woman is shown standing alone in her boyfriend's childhood bedroom, his toys and furniture returned to the state they were in decades ago. In the next shot, the frame pulls back to reveal a doorway across the hall through which the young woman finds her boyfriend's mother having advanced in age many years, her son spoon feeding her now feeble, wheelchair-confined form. Not only does the latter shot provide spatial continuity as the 
woman moves from room to room, but it also connects past and future realities through the continuous figure of the woman, who the spectator interprets to be existing in the present. In this way, the very language of the film serves to relate disparate shot-/time-layers even in the absence of dialogue or other explicit indications of their association.

It is evident in discussing the above conceptions of filmic significance and shot construction that the lived experience of the spectator is critical to even the most fundamental aspects of cinema. Although the intratextual level of the cinematic palimpsest deals primarily with the arrangement of the shot-layers, the spectator is yet to be woven into even these basic compositions. Suture theory can help to address this phenomenon further by "attempt[ing] to account for the means by which subjects emerge within discourse" (Silverman 137). Classical suture theory explains how the spectator is aligned with the perspective of the Absent One, who occupies an implied space just beyond the limits of the frame at any given moment. This stitching together of perspectives, involving an active awareness of the absent field on the spectator's part, is the prerequisite for signification, according to suture theorist Jean-Pierre Oudart. In the context of the palimpsest, the "stitch" can be thought of as the locus or "zone of contact" of the spectator's embodied dialogue with the text, the alignment of the spectator with a particular perspective never to be divorced from the lived experience of viewing (The Dialogic

\section{Imagination 7).}

In every shot of a film, there exists an implied off-screen area just behind the camera from which the perspective of the shot is derived. This "absent field," forms an in(ter)dependent relationship to what is visible on-screen because they are two parts of an albeit invisible whole beyond the frame (Oudart 39)."Although remaining empty when [the spectator] vanishes into the filmic field," the absent field " must nevertheless be kept for him [sic] throughout the film" in 
order to remain coherent, meaning that we must always imagine this unseen space even as we see its opposite within the shot (38). Significance in cinema can only be elucidated in the realization of the "duality of its space," the signifier arising from the "mutual articulation" of both the present (visible) and absent (invisible) fields (44). The Absent One is a theoretical construct indicating the place of the viewing subject within the absent field, from whose perspective the contents of the frame arise. Although obviously not synonymous with the spectator, the Absent One and the spectator share the same field of vision in any given shot, opening up a common space or standpoint from which dialogue between text and spectator arises. These two parties, one imaginary and one inhabiting a physical space of viewing, are reconciled in the process of the suture, which is "the abolition of the Absent One and its resurrection in someone" outside the text itself (37).

The reconciliation of the spectator and the Absent One is often discussed as taking place primarily or exclusively within shot/reverse-shot formations, as "the second shot shows the field from which the first shot is assumed to have been taken," making obvious the position of the Absent One and allowing the spectator to imagine themself there with ease (Silverman 138). While the palimpsest model recognizes that shot/reverse-shot sequences do stitch the spectator's perspective into the diegesis of the text, this occurs to no greater or lesser extent than in any other type of shot or shot construction, from a static long take to a rapid montage sequence. Even a shot composed entirely of abstract imagery, as in an experimental film or video art, yet suggests an unknown position existing just off-screen through its reflexive attention-calling to the false limits of the frame. Just as the palimpsest model is not applicable exclusively to certain genres, movements, nations, or filmmakers in cinematic history, suture theory and its implications for the spectator are not confined to a specific set of films or shot constructions. The 
spectator is always entering into the phenomenon of the palimpsest in watching a film, and always being stitched into the perspective of the Absent One that perceives the scene before them.

\section{Texts in Conversation in the Intertextual Palimpsest}

While all of this applies to the intratextual level of the cinematic palimpsest, the model is made up of much more than individual films or shot sequences. At the intertextual level of the palimpsest, additional layers of significance are added to the text in the form of related texts such as prequels, sequels and remakes, which expand narratives established by a primary text, other films that pay homage to a text or belong to the same body of work or film movement, or alternate media paratexts such as trailers, DVD extras and commentaries, and ancillary merchandise. Paratexts can be thought of in the current consumer-driven media landscape of Hollywood as "texts that prepare us for other texts" (Gray 25). They implicitly indicate the genre, tone, audience demographic, and cultural predecessors of some other ultimate product

they are designed to promote, such as a trailer might be intended to market an upcoming feature film. In the capitalist industries of Hollywood, paratexts are often created to tell us what entertainment products are available for consumption and why we should spend our money on them. They also contribute to the interpretations we as spectators derive from texts, however, fan-generated paratexts such as criticism and fan fiction allowing spectators to manipulate the narrative of a text for under their own total control and for their own purposes (143). While a paratext constitutes a text of its own when taken up as a primary object of study, they also serve as layers of originary palimpsests like feature films when used by spectators to alter or add to the meaning of the latter. 
It follows that paratexts' effect on the significance of any primary text is tempered by the spectator's active combination or structuring of various paratexts to curate their own complex experience as media consumers. Whereas Jonathan Gray argues that paratexts can fall into several categories ("entryway paratexts," "in medias res paratexts," "incorporated" and "unincorporated" paratexts, and so on) depending on the context in which a spectator encounters them, the spectator-driven palimpsest suggests that no such fixed distinctions occur outside of the spectator's own self-directed organization of textual and paratextual layers $(35,215)$. Gray also asserts that marketing-based paratexts such as trailers "serve a vital indexical purpose" in relation to the feature films they are paired with (52). While this may be true for the intents and purposes of the consumer machine, the palimpsest cannot recognize indexical relationships among its layers by virtue of their in(ter)dependency on one another to create meaning. At the intertextual level, as on the intratextual level, the palimpsest recognizes no fixed or singular meaning inherent to any one of its layers or collections of layers, and therefore cannot support a hierarchical relationship between texts and their corresponding paratexts.

Relationships between feature film texts and other feature film texts that may include references or homages to each other are also important when considering the significance of a particular work. Major historical film movements such as the French New Wave explicitly sought to generate meaning via the layering of intertextual references among the works of a small group of filmmakers. Latin American Third Cinema, too, commonly referenced other anticolonial films and literature in its subversion of the sociopolitical order. Filmmakers throughout history have "frequently [made] use of the cultural images and language of previous epochs" in their work, sometimes without being conscious of doing so (Eisenstein 115). How often this still occurs unconsciously in the current age of convergence culture and collective 
intelligence is up for debate, however. In any case, all cinema involves some level of intertextuality, if only by virtue of the codified use of film language across time periods and cultural contexts. Unlike texts and their associated paratexts, separate feature texts are not necessarily related to each other beyond the connections a spectator might make between them. Thus, they illustrate more clearly the active role of the spectator in conceptualizing a palimpsest for themself, as opposed to following some interpretation of a text or set of texts predetermined by industry forces or marketing packages.

Gérard Genette refers to "hypertextuality" as a form of intertextuality wherein "a text [is] derived from another preexistent text" (5). Even within a single text, however, various states of construction such as drafts or initial notes function as a hypertext to one another, the entire palimpsestuous process of creating a text being "a matter of auto-hypertextuality" on behalf of the filmmaker-author (395). Drawing from the literary theories of Bakhtin, Kristeva's structuralist concept of intertextuality views the individual element of a work (the word or the shot) not as a fixed sign, but "as an intersection of textual surfaces... a dialogue among several writings: that of the writer, the addressee (or the character) and the contemporary or earlier cultural context" (35-36). This means that, as Genette suggests, intertextuality manifests not only in the spaces between texts, but also at the intangible site or palimpsest of each individual text. At the intratextual level of the palimpsest, the shot is "defined horizontally" in relation to the shots surrounding it, as well as "vertically," as it relates the text to a larger cultural body of work (Kristeva 36-37). Kristeva "assumes an examination of interconnections between texts that situates the making of meaning in and through a dialogic process that occurs between the text and audience," again emphasizing the importance of the spectator in making connections between text-layers (Raj 80 ). The dualistic nature of cinematic language can be understood "in 
terms of one and other," harkening back to Oudart's doubling of the image in the absent field and the doubling of the spectator in the place of the Absent One (40). While connections from text to text bear significance, the connection between text and audience or individual spectator is the necessary mechanism of intertextual significance.

In addition to paratextual and intertextual relationships, the intertextual level of the palimpsest also deals with relationships between texts and their production contexts or authorship. While the palimpsest contradicts the idea that authorship or an auteur vision alone can comprise the total significance of a text, a director or writer's contributions can certainly make up one of the many layers that spectators use in determining the significance of a text. Authorship can be made more or less obvious to a spectator, a director's recognizable style or direct mention of the filmmaker in the text being examples of apparent authorship. Like the palimpsest itself, evidence of authorship in a text belies a formalist narrative strategy that "make[s] viewers aware of how easily cinema prompts them to mistake appearances for reality" (Young 114). Examples of the role of authorship in the palimpsest model can be found in the oeuvres of many directors, including the early 20th century films of Lois Weber, a pioneering female filmmaker who integrated her personal identity and brand into her films.

The 1915 film Hypocrites opens on a portrait of Weber reclining in a chair, the realist presentation of the still photograph recalling the epistemic authority of a newspaper or other official publication. Her image is accented by a pseudo-handwritten signature spilling across the bottom of the frame, as though in direct personal address from Weber to the audience. From this point in the film, spectators are introduced to the cast of characters and the archetypes they represent, each archetype indicated by costuming and title as they appear on screen one by one. They are not "psychological characters capable of self-definition," but instead function almost as 
game pieces moved around the narrative by their ever-present author-God (Young 105). In this way, spectators are forced to consider the author's overt ideological intentions as another layer alongside the fictional narrative of the text. In Federico Fellini's 1987 Intervista, too, spectators are presented with a story not only referencing its author, but in many ways about its author's life and work. In one scene, frequent Fellini players Marcello Mastroianni and Anita Ekberg join the director to watch their infamous Trevi Fountain scene from 1960's La Dolce Vita. For any viewer familiar with his body of work, this moment calls to mind layers of significance related to Fellini's style, themes, and past films. Deleuze has referenced Fellini's penchant for such selfreflexive scenes as a form of crystal-image "which is always in the process of formation, expansion," and with "a capacity for indefinite growth" as an intertextual palimpsest spanning his entire oeuvre (89).

\section{Intersubjectivity and the Extratextual Palimpsest}

On the extratextual level, the palimpsest model describes how spectators themselves enter into the in(ter)dependent structure of the palimpsest and why exactly the perception and sensory experience of the spectator is necessary to the functioning of the model. "This is a cinema of the seer and no longer of the spectator," proclaims Deleuze in Cinema II, alluding to the spectator's role as both viewing subject and active participant in the cinematic experience (2). The "seer" is a subject of as infinite variety as the layers of the palimpsest, never to be conceived of as an ideal but as a living person with an identity and past experience. Stuart Hall details how spectator positioning affects the transmission of meaning from a text, or rather the exchange of meaning that takes place between text and spectator. We know that differences among spectators, especially in terms of demographic categories such as ethnicity, gender, and socioeconomic 
status, all change how the individual viewer interprets a text both intentionally and unconsciously. For one thing, these differences may change the points of identification for a given spectator with specific characters or events in a film. Additionally, they may change the ways in which a given spectator understands the meaning of a film based on their unique viewing position and inclination to adhere or not adhere to the dominant ideology of the text. Such differences among spectators are necessary in the palimpsest model, as no essential subject can exist within a fluid phenomenon that is dependent on the perception of the individual spectator to signify. As in Derrida's différance, the spectator cannot be "constituted by" the text, but the phenomenon of the text is constituted by the spectator (15).

Reconsidering the theories of Epstein, we find a justification for the spectator's active role in the meaning-making of any cinematic text. The individual shot-layers or paratexts of any given text do not form a whole of significance on their own, although the illusion of such a phenomenon is part of what characterizes cinema and draws audiences to the medium. Rather, the spectator consciously transforms the discontinuities of disparate parts into the continuity of the whole through their own sensation of a film (The Intelligence of a Machine 10). Hall refers to this transformation as a decoding, one step in the larger, circular process of meaning-making in video media. If Metz's spectators are simply users of a predetermined film language, Hall's conception of the meaning-making process in media posits spectators as the equal and active partners of content producers such as directors or writers. That Hall's work, which focuses primarily on non-narrative media such as news, should apply so well to narrative film is an indication of the versatility of both his encoding-decoding model and the theoretical framework of the palimpsest that it helps define. 
Spectators can fall into three general categories of viewing positions or alignments according to Hall. The "dominant-hegemonic position" refers to spectators reproducing in their own interpretations the "institutional/political/ideological order" encoded in the text by the ideological powers that be (169-171). Next, the "negotiated position" is somewhat less adherent to institutionalized codes, "accord[ing] the privileged position to the dominant definitions of events while reserving the right to make a more negotiated application to [the] 'local conditions"” of the spectator's subject position (172). Finally, the "oppositional position" reworks the privileged code "to retotalize the message within some alternative framework" provided by the spectator (173). These categorizations describe the lived experience of Bakhtin's concept of heteroglossia, or the "coming to know one's own [the spectator's] horizon within someone else's [the text's] horizon" through dialogue (The Dialogic Imagination 365). Just as in interactions between people using spoken language, cinematic spectators necessarily engage with a text through the lens of inherent ideologies borne of occupation, age, ethnicity, language, geography, and social groups, which are triangulated within individuals to produce a unique discursive outlook (Park-Fuller 1). Where a spectator falls along the spectrum of decoding positions depends on the oftentimes asymmetrical ideological outlooks of the "encoder-producer and decoder-receiver," meaning that similar ideological systems supported by both parties would likely result in a dominant-hegemonic interpretation (so long as the text itself subscribes to dominant ideology), while smaller or greater ideological differences among the two parties would result in negotiated or oppositional readings (Hall 166). This process of decoding is the "hermeneutic activity of the reader," also termed "archireader," attested to by Genette (9).

Returning briefly to Oudart's suture theory, we can view the spectator's relationship to the text on the extratextual level as a sort of self-directed suturing. Instead of the text 
commanding the spectator into alignment with a particular character or set of perspectives, the spectator is seen as having a degree of control over their own alignment or non-alignment with what appears on screen. While the image presents a fixed spatiotemporal point of view, the spectator is capable of forming their own subjective ideological response to all visual and auditory stimuli presented. In the palimpsest model, the text is not "structured from the point of view of a nonparticipating 'third person"' such as the Absent One, but from the point of view of a figurative Absent One-like entity that cannot be separated from the embodied spectator themself, even in a theoretical sense (Problems of Dostoevsky's Poetics 18). The embodied experience of the spectator always implies a unique viewing subjectivity that affects the text's meaning, not in the sense of altering the literal image, but of interpreting it to speak in ways that its author may not have intended. With no spectator viewing a film text to begin with, there can be no point of view whatsoever. The spectator is "the actor in a representation whose symbolic dimension is revealed in the process of reading and viewing" (italics mine), not a passive placeholder for the Absent One's ideal perspective (Oudart 35).

An example of the spectator's active role in meaning-making can be found in Michaela Coel's 2020 HBO series I May Destroy You. The show depicts experiences of sexual assault on behalf of several characters, including some who do not learn until later scenes that what has occurred is considered to be a criminal offense. With a clear social justice aim, evidenced in the narrative and by the resource website for survivors that appears at the end of each episode, I May Destroy Үou opens up a space for the spectator to reflect on their real life experiences, recontextualizing their own memories and interpreting the televisual text in the light of emotions and physical affects brought to the surface in the course of an intersubjective viewing praxis. While the medium of TV poses unique problems for the application of the palimpsest model, 
including the complexities of layering between multiple episodes that lie somewhere in between the intra- and intertextual levels of the viewing experience, the principle of in(ter)dependency and the necessity of the sensing spectator remain consistent between films and the typical television series. The unique history of $\mathrm{HBO}$ as a cinema streaming service now producing original auteur-driven, high-budget programming suggests that at least titles under the HBO channel heading may be considered "cinematic" enough to be put in conversation with feature films for the purposes of this study. Streaming content is also generally tied to binge-watching, wherein a spectator's experience of viewing the entire TV text in one sitting would approximate cinematic viewing praxis.

If every unique spectator supplies their own unique and active decoding of a given film, it follows that the spectator themselves is yet another of the layers comprising the palimpsest model. In fact, the spectator themself is the only specific layer which is necessary to the ontology of the palimpsest, all others being practically interchangeable within the larger structure of the model. Rather than there being any one ideal spectator or position for a spectator to inhabit in viewing a film, the spectator themself bears an agency in the meaning-making process reflective of their unique subjectivity. Unlike apparatus theory, which defines spectatorship as the alignment of one's perspective with the narratological perspective of the film within the physical arrangement of the theater apparatus itself, the palimpsest allows for any number of ideological and demographic spectator positions, even those which actively subvert the dominant or monologic perspective. This is a reworking of the "message in the preferred code" or layer of the spectator, rather than the filmmaker, the text itself being a neutral site of dialogical exploration (Hall 103). Eisenstein, too, recognizes the multiplicity of spectator interpretation, stating that "the conflict of social conditionality" and previous life experience and subject positioning of the 
spectator can lead to various readings of the text's dominant message, including an "a-dominant" reading similar to Hall's oppositional position $(48,68)$. Eisenstein departs from Hall, however, in his assertion that the spectator enters a "desired condition" in following the interpretative path indicated by the auteur/director "guide," overriding the individual experience of each spectator in favor of some dominant message (168). No such hierarchy of assigning significance can exist within the palimpsest, which seeks to level the discursive powers of creator and consumer. Eisenstein also struggles to decide in his early writings whether the so-called purpose of cinema is to convey intellectual or emotional significance to the spectator, and by which method social change can best be enacted (62). What he did not conceive of was the fulfillment of his ultimate "synthesis of art and science" in the palimpsest, which views both intellectual and emotional significance, along with bodily affective responses, as occurring simultaneously and being equally important to the lived cinematic experience of the spectator-layer (63).

Particularly in the current digital age, we must make note of the fact that the palimpsest model is not confined to the physical setting of the movie theater, whether a one-screen arthouse theater or a suburban multiplex. Those watching films at home, with differing sound systems and screen sizes, or even out in public with a cell phone and a pair of earbuds, all experience equally rich and complete palimpsests of a given text, despite each being entirely unique to the moment in which they occur. Cult viewing praxis, which often includes forms of spectator engagement foreign to typical film viewing such as throwing props or dressing as favorite characters, is yet another equally significant type of layer. Even the same spectator watching the same text at a new stage of life or in a different emotional state may vastly alter the unique significance of the spectator-layer. The categorizing function of streaming services and new types of paratexts such as the mobile advertisements only serve to multiply the paradigms available to the average 
spectator in the 21st century. But while physical or emotional affect derived from differences in setting diversify the experience of the spectator, just as no ideal spectator can exist, neither can any ideal viewing praxis or context. As these new modes of spectatorship become increasingly common, the palimpsest's egalitarian approach may come to instruct thinking on the topic of popular consumption of 21 st century media, which has already been widely noted for its capacity for highly individualized, curated interfaces and content delivery using algorithms based on viewing history and other metrics. The palimpsest may prove to be a key to understanding the proliferation of spectator-driven, rather the narrative or studio-driven texts moving forward into this emerging era of media consumption.

So, what is the greater import of each spectator's unique experience of viewing and decoding in the real world, outside the physical or discursive space of the theater (or home theater, or mobile "theater," etc.)? The significance of a cinematic palimpsest is not confined to the environment in which a text is experienced but has the capacity to change broader patterns of behavior and discourse perhaps unrelated to the original text. "The "message" of a film, "via its decodings, issues into the structure of social practices" that affect not only the individual spectator, but a larger group of people who may not be able to trace the changes to their subjectivities back to the original text at all (Hall 165). The text and its reception are dialogically linked "in a continual renewing of the work through the creative perception of listeners and readers," who are constantly adding their own layers of significance to an infinite discursive palimpsest (The Dialogic Imagination 254). Such patterns of transmission are already evident in our modern praxes of media consumption. In the late 20th century, for example, the first online chat rooms organized fans around particular texts such as Lost as they shared opinions and consulted with one another on the series' puzzles in an ongoing act of community decoding 
(Gray 140). While the palimpsest may be confined to the layers surrounding a particular work, seemingly interminable as they may be, what the spectator derives from an experience of a cinematic palimpsest is truly boundless, influencing theirs and others' behaviors and patterns of thought in settings far removed from the site of the initial text. This effect of the experience of the cinematic palimpsest acts as a trace, or "simulacrum of a presence that dislocates itself, displaces itself, refers itself" and "has no site" within a specific shot, film, or spectator (Derrida 24). Rather, the trace circulates among a cultural discourse and body of other artistic works indefinitely alongside any number of spectators throughout time. In our current day and age, as the lived experience of media so often involves engagement with intermedial and interactive platforms, the palimpsest demonstrates the spectator's agency in the meaning-making process and the means of their entering into a structure of such transience and intangibility beyond an initial text.

\section{The Layers to Come}

From the intratextual to the intertextual and extratextual levels, the palimpsest outlines a new model of how cinematic significance is generated between screen and spectator. In an increasingly intermedial 21 st century landscape, the palimpsest elucidates the intersections of the human mind and the media technologies it encounters on a regular basis. Most importantly, it resists notions of singular or objective significance in favor of multiplicitous, intersubjective experiences of meaning creation more fitting to the current postmodern era of cultural and artistic scholarship. Further applications for the cinematic palimpsest alone are numerous, from enriching demographic-based reception studies and inquiries into cult fandom, to fostering new discussions around bodily affect and phenomenological responses among spectators of all 
varieties. For the palimpsest as a theoretical concept in general, however, areas for further applications in art and academia are practically infinite. After all, the principle of in(ter)dependency and the basic relationship of text to spectator that exists in the cinematic palimpsest have their counterparts in the fields of visual arts, dance and choreography, social media, gaming, news media, literature, and so on, including intermedial combinations thereof. The rise of streaming, and especially of the ever-evolving world of television, provide particularly fruitful spaces for the application of the palimpsest model due to their many similarities to cinematic viewing praxis. As the model evolves and is applied to theories and disciplines new and old, it will continue to form its own infinite discursive palimpsest in and of itself, each new area it touches serving as a meta-layer of its own overarching structure as a theoretical concept.

The medium of cinema is a recent invention in the history of human arts and culture. We have yet to definitively assign its ontology to any one set of theories or understandings, and the palimpsest model does not seek to finalize any such questions, despite the richness of understanding it has to offer the cinematic experience. On the contrary, the palimpsest is indicative of the uniqueness of every individual's experience of the cinema and the according infinitude of meaning and relationships that can exist between text and spectator. No longer can we conceive of the cinematic text's transmission of its monologue to a group of passive listeners. The cinema is now, as it has always been and forever will be, an infinite, intangible, and "unthinkable" palimpsest manifesting in the interstices of the screen and the perceiving human mind (Derrida 19). 
1. The scientific Principle of Complementarity was outlined by Niels Bohr in the 1920s to describe how mutually exclusive states can occur simultaneously in quantum physics. Using the primary example of the perception of light, which exists at all times as both a particle and wave, he states that the two opposite states are impossible to observe simultaneously and yet hold true simultaneously, giving a more truthful picture of the phenomenon than either one can alone (Bohr 366). The same can be said for the model of the cinematic palimpsest, in which irreconcilable past and future temporalities are shown to signify simultaneously for the spectator. Of course, film and the light phenomena Bohr studied are vastly different media, with vastly different temporalities, modalities, and means of operation and perception by an outside party. Because it cannot account for the type of qualitative, subjective interpretation performed by spectators in the palimpsest model, Bohr's Principle of Complementarity is not a perfect theoretical model of in(ter)dependency in the cinema. Nevertheless, it can help us understand the basic structure of the palimpsest and function as a cross-disciplinary theoretical model of meaning-making, rather than a literal analogy to any one form of art of science. 


\section{Works Cited}

Aumont, Jacques, et al. Aesthetics of Film. Translated by Richard Neupert, E-book, University of Texas Press, 1992.

Bakhtin, Mikhail. The Dialogic Imagination, edited by Michael Holquist, translated by Caryl Emerson and Michael Holquist, E-book, University of Texas press, 1981.

---. Problems of Dostoevsky's Poetics, edited and translated by Caryl Emerson, E-book, University of Minnesota Press, 1984.

Baudry, Jean-Louis, and Alan Williams. "Ideological Effects of the Basic Cinematographic Apparatus.” Film Quarterly, vol. 28, no. 2, 1974, pp. 39-47. JSTOR, https://www.jstor.org/stable/1211632. Accessed 27 Jan. 2021.

Bohr, Niels. "Discussion with Einstein on Epistemological Problems in Atomic Physics." Foundations of Quantum Physics II (1933-1958), edited by Jørgen Kalckar, Elsevier Science B.V., 1996, pp. 339-381.

Coel, Michaela, creator. I May Destroy You. Various Artists Limited and FALKNA Productions, 2020.

Deleuze, Gilles. Cinema II: The Time-Image. Translated by Hugh Tomlinson and Robert Galeta, University of Minnesota Press, 1989.

Derrida, Jacques. "Différance.” Margins of Philosophy, translated by Alan Bass, University of Chicago Press, 1982, pp. 3-27.

De Quincey, Thomas. “The Palimpsest of the Human Brain.” Suspira de Profundis, E-book, Shepard and Gill, 1873, pp. 10-22.

Dillon, Sarah. “Reinscribing De Quincey’s Palimpsest: The Significance of the Palimpsest in Contemporary Literary and Cultural Studies." Textual Practice, vol. 19, no. 3, 2005, pp. 
243-263. Taylor \& Francis Online, doi: 10.1080/09502360500196227. Accessed 11 June 2020.

Eisenstein, Sergei. Film Form: Essays in Film Theory, edited and translated by Jay Leyda, Harvest, Brace \& World, Inc., 1949.

Epstein, Jean. “On Certain Characteristics of Photogénie." Jean Epstein: Critical Essays and New Translations, translated by Tom Milne, E-book, Amsterdam University Press, 2012, pp. 292-296.

---. "The Interchangeability of Continuity and Discontinuity." The Intelligence of a Machine, translated by Christophe Wall-Romana, E-book, University of Minnesota Press, 2014, pp. 7-16.

Genette, Gérard. Palimpsests: Literature in the Second Degree. Translated by Channa Newman and Claude Doubinsky, E-book, University of Nebraska Press, 1997. Gray, Jonathan. Show Sold Separately: Promos, Spoilers, and other Media Paratexts. E-book, New York University Press, 2010.

Hall, Stuart. “Encoding/Decoding.” Media and Cultural Studies: Keyworks, edited by Meenakshi Gigi Durham and Douglas M. Kellner, 2nd ed., Blackwell Publishing, 2006, pp. 163-173. Hypocrites. Directed by Lois Weber, Paramount Pictures, 1915.

I'm Thinking of Ending Things. Directed by Charlie Kaufman, Netflix, 2020.

Intervista. Directed by Federico Fellini, Castle Hill Productions Inc. and Koch-Lorber Films, 1987.

Kristeva, Julia. "Word, Dialogue and Novel." The Kristeva Reader, edited by Toril Moi, Columbia University Press, 1986, pp. 34-61. 
Metz, Christian. "Some Points in the Semiotics of the Cinema." Film Theory and Criticism: Introductory Readings, edited by Leo Braudy and Marshall Cohen, 5th ed., Oxford University Press, 1999, pp. 68-75.

Oudart, Jean-Pierre. "Cinema and Suture." Screen, vol. 18, no. 4, 1977, pp. 35-47, https://doi.org/10.1093/screen/18.4.35. Accessed 13 June 2020.

Park-Fuller, Linda M. "Voices: Bakhtin's Heteroglossia and Polyphony, and the Performance of Narrative Literature." Literature in Performance, vol. 7, 1986, pp. 1-12. CSUN, http://www.csun.edu/ vcspc00g/604/voices-lpf.html. Accessed 1 July 2020.

"Pentimento." OED, https://www-oedcom.libproxy.chapman.edu/view/Entry/140353?redirectedFrom=pentimento\&. Accessed 13 Feb. 2021.

Peucker, Brigitte. Incorporating Images: Film and the Rival Arts. E-book, Princeton University Press, 2014.

Raj, P. Prayer Elmo. “Text/Texts: Interrogating Julia Kristeva's Concept of Intertextuality.” Ars Artium, vol. 3, Jan. 2015, pp. 77-80. ResearchGate, https://www.researchgate.net/publication/273771676_TextTexts_Julia_Kristeva's_Concep t_of_Intertextuality. Accessed 24 June 2020.

Silverman, Kaja. "On Suture." Film Theory and Criticism: Introductory Readings, edited by Leo Braudy and Marshall Cohen, 5th ed., Oxford University Press, 1999, pp. 137-147.

Toubiana, Serge. "The Brain is the Screen: Interview with Gilles Deleuze on the Time-Image.” Discourse, vol. 20, no. 3, 1998, pp. 47-55. ProQuest, https://search.proquest.com/docview/212436015?accountid=10051. Accessed 8 June 2020. 
Young, Paul. "Yours Sincerely, Lois Weber: Hypocrites and the Allegorical Mode of the Transitional Feature Film.” Cinema Journal, vol. 55, no. 1, 2015, pp. 95-119. Project Muse, doi: 10.1353/cj.2015.0061. Accessed 17 June 2020. 